\title{
WAVE AND DISSOLVED OXYGEN TRANSMISSION ANALYSIS IN HARBORS USING FLUSHING CULVERTS: AN EXPERIMENTAL APPROACH
}

\author{
V.K. TSOUKALA ${ }^{1, *}$ \\ C.K. GAITANIS ${ }^{2}$ \\ A.I. STAMOU ${ }^{2}$ \\ C.I. MOUTZOURIS ${ }^{1}$
}

Received: 18/06/09

Accepted: 30/11/09

\author{
${ }^{1}$ Laboratory of Harbor Works \\ ${ }^{2}$ Laboratory of Applied Hydraulics \\ School of Civil Engineering, \\ National Technical University of Athens (NTUA), \\ Iroon Polytechniou 5, 15780 Athens, Greece
}

*to whom all correspondence should be addressed: e-mail: tsoukala@mail.ntua.gr

\begin{abstract}
One of the most favorable and cost-saving methods to counteract water quality deterioration in a harbor basin is the use of flushing culverts, which reduce flushing times and avoid areas of low flow and eddies formation. In the present paper, results of experiments carried out in a 2-D facility in order to investigate wave and dissolved oxygen transmission in harbor basins through flushing culverts are presented and analyzed. Incident wave and transmitted wave heights were determined using wave gauges for various combinations of wave characteristics and geometric characteristics of the flushing culverts. An empirical equation using regression analysis was derived, which correlates the wave transmission coefficient with the characteristics of the waves and the geometrical characteristics of the flushing culvert. Further the oxygen transmission coefficient through flushing culverts, was expressed as a function of the characteristics of waves and the dimensions of the flushing culvert. The comparison of calculated and experimental data is very encouraging. Though, the verification of the proposed equation with even more extended experimental data and real scale measurements is needed in order to be used in the design process.
\end{abstract}

Keywords: transmission coefficient, water quality, coastal structure, flushing culvert.

\section{INTRODUCTION}

Marine pollution in coastal areas is a subject of global interest the last decades, as the development of large metropolises, harbors and industrial, developed traditionally in the coastal areas, resulting in the deterioration of neighboring marine environments (Nikolaou et al., 2009). Water quality within a basin must be considered, especially in warmer climates where biological processes are accelerated. Dissolved oxygen concentrations and eutrophication, are of the most studied forms of coastal marine pollution (Tsoukala and Moutzouris, 2009; Karydis, 2009). Successful control of water quality is usually dependent upon periodic exchange of harbor water with the main water body that the harbor serves (Dunham and Finn, 2002; US Army Corps of Engineers, 2002). Several methods have been developed to counteract diminished flushing and insufficient renewal occurring leeward of coastal structures (EPA, 2001). Among these methods, providing openings through the construction of flushing culverts is favorable due to the low construction and operational costs.

In Greece, where there are more than 600 harbors of different sizes and operations, the construction of flushing culverts for the improvement of water quality is common (Tsoukala and Moutzouris, 2009). Two factors seem to have a significant role in water quality using flushing culverts: wave transmission and dissolved oxygen transfer. The first one counts for enhancing water transfer rate through the narrow openings of flushing culverts and thus diminishing renewal time, whereas DO transfer represents a more direct index of water quality. 
Several efforts have been made to demonstrate the beneficial effects of designing flushing culverts using numerical models (Stamou et al., 2004; Foudoulis and Memos, 2005). Recently, experimental results in 3-D experimental facilities (Tsoukala and Moutzouris, 2003) at the Laboratory of Harbor Works (LHW) of National Technical University of Athens (N.T.U.A.) have been presented. The wave transmission coefficient $\mathrm{K}_{t}$ (defined as the ratio of the transmitted wave height to the incident wave height through the flushing culvert) was used as the main nondimensional parameter and it was correlated with the wave characteristics (wave height and wave period) and geometrical characteristics of the flushing culvert using dimensional, parametric and regression analyses.

In this paper results of measurements conducted in a 2-D experimental facility in order to investigate wave and dissolved oxygen transmission in harbor basins through flushing culverts are presented and analyzed. A constitutive set of experiments was carried out to observe the effect of the geometrical characteristics of flushing culverts on the wave transmission coefficient in order to define which parameters could most effectively predict the wave transmission coefficient. Furthermore, the experimental data were processed using regression analyses. As a result, empirical equations that can be used in the design of flushing culverts were derived. The proposed equations correlate the wave transmission coefficient and the oxygen transfer coefficient respectively to the characteristics of flushing culverts and to the incident wave characteristics.

\section{EXPERIMENTAL SETUP AND DATA SAMPLING \\ 2.1 The physical model}

Physical model experiments were conducted in the wave flume at the Laboratory of Harbour Works (LHW) of National Technical University of Athens (NTUA). The flume is $27 \mathrm{~m}$ long with a rectangular cross-section that is $0.60 \mathrm{~m}$ wide and $1.52 \mathrm{~m}$ high (Figure 1). A piston-type wave generator is fixed at the one end of the flume and is capable of producing monochromatic, sinusoidal waves. The input signal to the wave generator is produced by modifying the velocity and the eccentricity of the wave paddle.

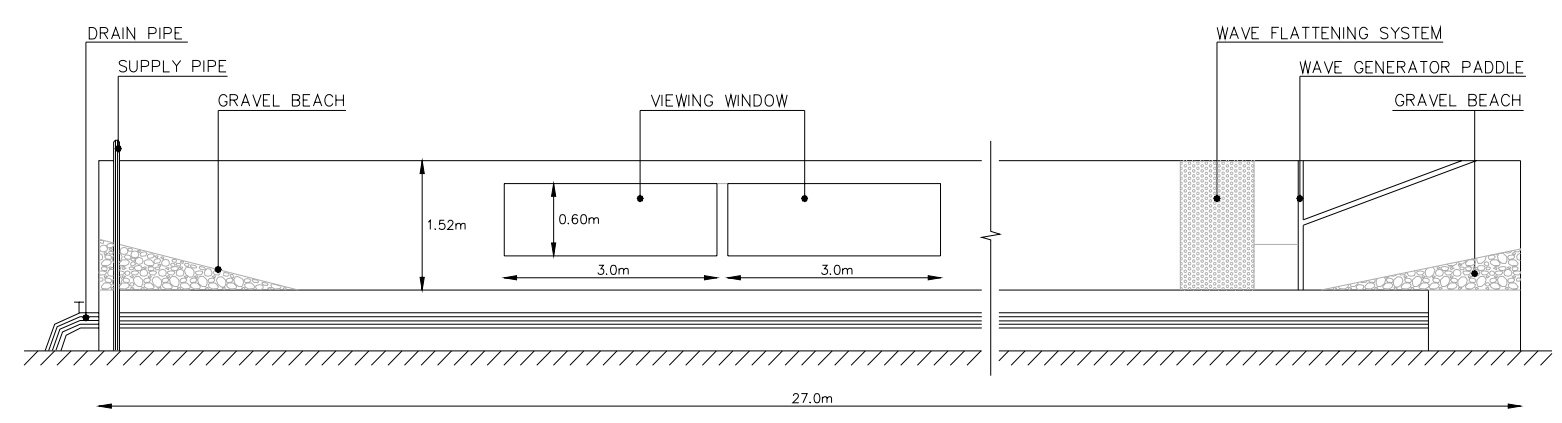

Figure 1. Schematic plan view of experimental flume

\section{$2.2 \quad$ Test layouts and structures}

Two different types of breakwaters were tested:

a) Rubble mound breakwater $(R M B)$ with a length of $1.80 \mathrm{~m}$, a height of $0.90 \mathrm{~m}$ and a width of 0.60 $\mathrm{m}$, equal to that of the flume. The breakwater was composed of a layer of quarry rocks with a density of $26.50 \mathrm{~kg} \mathrm{~m}^{-3}$ and characteristic diameter $d_{50}=12 \mathrm{~cm}$. The rocks had varying dimensions and a fixed length of $1 \mathrm{~m}$ for all the layouts. The leeside of the breakwater was constructed by a steel vertical plate of $2 \mathrm{~mm}$ thickness. Flushing culverts were placed inside the breakwater with varying width (b) and height $(\mathrm{h})$ and constant length $(\ell=100 \mathrm{~m})$. The still water depth for each layout is given in Table 1. All other major dimensions are given in Figure 2a.

b) Impermeable vertical breakwater (VB) with varying length and constant height and width (1.00 m $x 0.60 \mathrm{~m}$ ) were tested. The still water depth was $0.60 \mathrm{~m}$ for all the experiments. The breakwater model was placed with its seaward side in a distance of $13 \mathrm{~m}$ from the wave generator paddle as it seems in Figure $2 b$. 
Details of the 15 different layouts for both breakwaters and specifically the width (b), the height $(\mathrm{h})$ and the length $(\ell)$ of the flushing culvert, the water depth (d) and the elevation of the bottom of the flushing culvert ( $\mathrm{z}$ ) are shown in Table 1.

Table 1. Experimental layouts

\begin{tabular}{ccccccc}
\hline Layout & Breakwater & $\mathbf{b}(\mathbf{c m})$ & $\mathbf{h}(\mathbf{c m})$ & $\ell(\mathbf{c m})$ & $\mathbf{d}(\mathbf{c m})$ & $\mathbf{z}(\mathbf{c m})$ \\
\hline Layout A & $R M B$ & 12.0 & 12.0 & 100.0 & 54.0 & 54.0 \\
Layout B & $R M B$ & 18.0 & 12.0 & 100.0 & 54.0 & 54.0 \\
Layout C & $R M B$ & 30.0 & 12.0 & 100.0 & 54.0 & 54.0 \\
Layout D & $R M B$ & 18.0 & 12.0 & 100.0 & 60.0 & 54.0 \\
Layout E & $R M B$ & 18.0 & 18.0 & 100.0 & 60.0 & 51.0 \\
Layout F & $R M B$ & 24.0 & 15.0 & 100.0 & 60.0 & 52.5 \\
Layout G & $R M B$ & 24.0 & 18.0 & 100.0 & 60.0 & 51.0 \\
Layout H & $R M B$ & 30.0 & 15.0 & 100.0 & 60.0 & 52.5 \\
Layout I & $R M B$ & 30.0 & 18.0 & 100.0 & 60.0 & 51.0 \\
Layout J & $R M B$ & 12.0 & 12.0 & 100.0 & 66.0 & 54.0 \\
Layout K & $R M B$ & 18.0 & 12.0 & 100.0 & 66.0 & 54.0 \\
Layout L & $R M B$ & 30.0 & 12.0 & 100.0 & 66.0 & 54.0 \\
Layout M & $V B$ & 18.0 & 12.0 & 50.0 & 60.0 & 54.0 \\
Layout N & $V B$ & 24.0 & 12.0 & 50.0 & 60.0 & 54.0 \\
Layout O & $V B$ & 24.0 & 12.0 & 100.0 & 60.0 & 54.0 \\
\hline
\end{tabular}

\subsection{Wave transmission measurements}

Resistance wave probes were used to record and determine wave characteristics for each test. A quoted precision of $\pm 2 \%$ can be achieved with these wave probes. The HR Wave Data Calibration Module (Beresford et al., 2005) was used to calibrate the wave probes.

A total of 158 experiments were conducted under different combinations for 10 monochromatic wave climates in order to investigate wave transmission characteristics through the selected layouts. Wave height $\left(\mathrm{H}_{\mathrm{i}}\right)$ used in the experiments ranged from $1.1 \mathrm{~cm}$ to $16.6 \mathrm{~cm}$ and wave periods $\left(T_{i}\right)$ from $0.90 \mathrm{sec}$ to $1.48 \mathrm{sec}$. The list of the different wave conditions is presented in Table 2.

Water level time series were measured using five resistance wave probes. The probes were placed on specific stands at specified positions along the flume. For all the conducted experiments, the probes were placed perpendicular to the water surface along the axis of the flume. In Figure 2, the locations of the wave probes $\left(\mathrm{P}_{\mathrm{i}}\right)$ for the two different breakwater models are shown.

The HR Wave Data Calibration Module (Beresford et al., 2005) was used to calibrate the wave probes. Wave data were sampled at a rate of $30 \mathrm{~Hz}$. All experiments were run twice over a period of $307 \mathrm{~s}$ each time. The HR Wave Data - Data acquisition and analysis software program (Beresford et al., 2005) was used for data acquisition, and the output signals of wave probes were stored in different data files for each test for further analysis.

\subsection{Dissolved Oxygen Concentration Measurements}

Additionally, in order to investigate the dissolved oxygen (DO) transmission through flushing culvert and the variation of DO concentration in the leeside of the flushing culvert, 14 selected experimental conditions (DO1-DO14) from the above mentioned (Table 2) were repeated for layouts $\mathrm{M}, \mathrm{N}$ and $\mathrm{O}$. 
Table 2. Experimental wave conditions

\begin{tabular}{|c|c|c|c|c|c|c|c|c|}
\hline $\begin{array}{c}\text { Wave } \\
\text { Number }\end{array}$ & $\begin{array}{c}\mathrm{H}_{\mathrm{i}} \\
(\mathrm{cm})\end{array}$ & $\begin{array}{c}T \\
\text { (sec) }\end{array}$ & $\begin{array}{c}\text { Wave } \\
\text { Number }\end{array}$ & $\begin{array}{c}\mathrm{H}_{\mathrm{i}} \\
(\mathrm{cm})\end{array}$ & $\begin{array}{c}T \\
(\mathrm{sec})\end{array}$ & $\begin{array}{c}\text { Wave } \\
\text { Number }\end{array}$ & $\begin{array}{c}\mathrm{H}_{\mathrm{i}} \\
(\mathrm{cm})\end{array}$ & $\begin{array}{c}\mathrm{T} \\
\text { (sec) }\end{array}$ \\
\hline W1 & 1.1 & 0.90 & W25 & 5.1 & 1.25 & W49 & 10.1 & 0.90 \\
\hline W2 & 1.3 & 1.48 & W26 & 5.2 & 1.48 & W50 & 10.2 & 0.90 \\
\hline w3 & 1.6 & 1.48 & W27 & 5.3 & 1.10 & W51 & 10.3 & 0.90 \\
\hline W4 & 1.7 & 0.90 & W28 & 6.0 & 1.10 & W52 & 10.6 & 0.90 \\
\hline W5 & 1.8 & 1.48 & W29 & 6.2 & 1.25 & W53 & 10.6 & 1.25 \\
\hline W6 & 1.9 & 1.10 & W30 & 6.2 & 1.25 & W54 & 10.8 & 0.90 \\
\hline W7 & 1.9 & 1.48 & W31 & 6.5 & 1.48 & W55 & 10.8 & 1.10 \\
\hline W8 & 2.0 & 0.90 & W32 & 6.6 & 0.90 & W56 & 10.9 & 1.10 \\
\hline w9 & 2.5 & 0.90 & W33 & 6.7 & 0.90 & W57 & 11.0 & 0.90 \\
\hline W10 & 2.7 & 1.48 & W34 & 7.6 & 1.48 & W58 & 11.1 & 1.48 \\
\hline W11 & 2.9 & 1.10 & W35 & 7.6 & 1.10 & W59 & 11.5 & 1.48 \\
\hline W12 & 3.0 & 1.48 & W36 & 7.8 & 1.25 & W60 & 11.7 & 0.90 \\
\hline W13 & 3.5 & 1.10 & W37 & 7.9 & 1.48 & W61 & 11.8 & 0.90 \\
\hline W14 & 3.9 & 1.48 & W38 & 8.0 & 1.48 & W62 & 12.4 & 1.48 \\
\hline W15 & 4.0 & 0.9 & W39 & 8.4 & 1.48 & W63 & 12.9 & 1.10 \\
\hline W16 & 4.2 & 1.25 & W40 & 8.6 & 0.90 & W64 & 13.1 & 1.25 \\
\hline W17 & 4.3 & 0.90 & W41 & 8.7 & 1.48 & W65 & 14.0 & 1.06 \\
\hline W18 & 4.5 & 1.10 & W42 & 8.7 & 1.48 & W66 & 14.3 & 1.06 \\
\hline W19 & 4.5 & 1.48 & W43 & 9.2 & 0.90 & W67 & 14.4 & 1.06 \\
\hline W20 & 4.6 & 0.90 & W44 & 9.3 & 1.10 & W68 & 15.7 & 1.06 \\
\hline W21 & 4.6 & 1.06 & W45 & 9.5 & 1.25 & W69 & 15.9 & 1.48 \\
\hline W22 & 4.8 & 1.48 & W46 & 9.7 & 1.10 & W70 & 16.0 & 1.06 \\
\hline W23 & 4.8 & 0.90 & W47 & 9.8 & 1.06 & W71 & 16.6 & 1.48 \\
\hline W24 & 5.1 & 0.90 & W48 & 9.9 & 0.90 & & & \\
\hline
\end{tabular}

(a) Rubble mound breakwater

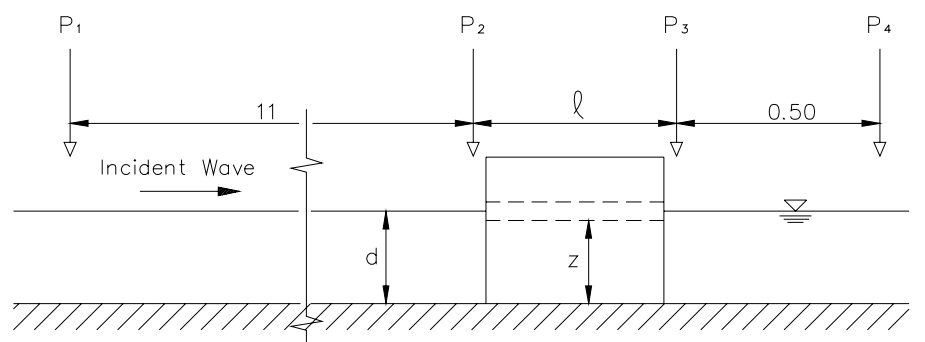

(b) Vertical Breakwater

Figure 2. Sketch of experimental setup 
Before each experiment, the water was deoxygenated using the nitrogen stripping method. Long elastic tubes with small pores were connected to nitrogen cylinders equipped with regulating pressure valves. The elastic tubes were placed in front and behind the breakwater. The deoxygenating procedure lasted $12 \mathrm{hrs}$ and the achieved concentration varied between 1-3 $\mathrm{mg} \mathrm{l}^{-1}$.

The concentration of DO in water body was monitored over time by a portable YSI 550 DO meter at 6 sampling locations $\left(\mathrm{O}_{1}-\mathrm{O}_{6}\right)$ along the flume as shown in Figure 2. Its precision varies around \pm $0.15 \mathrm{mg} \mathrm{I}^{-1}$. For measurements where water temperature varies from calibration temperature \pm 10 ${ }^{\circ} \mathrm{C}$, a systematic fault of $\pm 1 \%\left(0.08 \mathrm{mg} \mathrm{l}^{-1}\right.$ in $\left.25^{\circ} \mathrm{C}\right)$ is involved (YSI.com, 2010). Before the beginning of each experiment, the DO meter was calibrated and the initial DO concentration $\left(\mathrm{C}_{0}\right)$ was measured before the start of the experiment.

Measurements of DO concentration commenced upon initial wave generation and continued until the DO value was stabilized. The measurement duration varied from 20-164 min depending on the wave conditions and the geometrical characteristics of the flushing culvert.

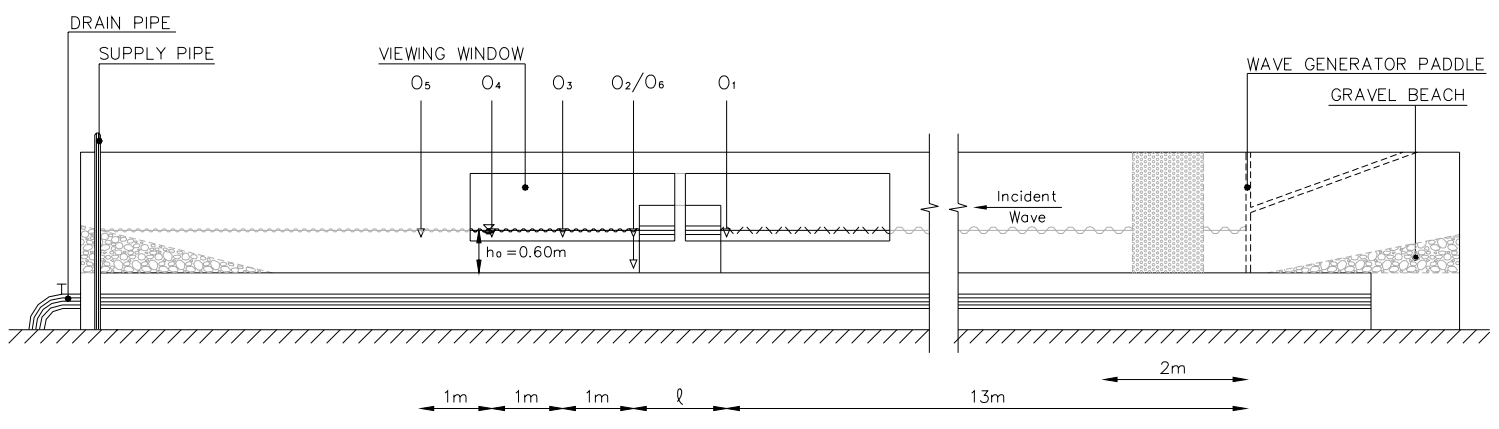

Figure 3. Dissolved oxygen concentration measurements locations

In Table 3, the characteristics of incident wave and geometrical characteristics of flushing culvert for the conducted experiments are shown.

Table 3. Wave and geometrical characteristics in experiments for DO measurement

\begin{tabular}{cccccc}
\hline \multirow{2}{*}{$\begin{array}{c}\text { No. of } \\
\text { experiment }\end{array}$} & \multicolumn{2}{c}{ Wave characteristics } & \multicolumn{3}{c}{ Geometrical characteristics } \\
& $\mathrm{H}_{\mathrm{i}}(\mathrm{cm})$ & $\mathrm{T}_{\mathrm{i}}(\mathrm{sec})$ & $\mathrm{b}(\mathrm{cm})$ & $\mathrm{h}(\mathrm{cm})$ & $\ell(\mathrm{cm})$ \\
\hline DO1 & 6.3 & 1.48 & 18.0 & 12.0 & 50.0 \\
DO2 & 10.7 & 1.48 & 18.0 & 12.0 & 50.0 \\
DO3 & 6.0 & 1.10 & 18.0 & 12.0 & 50.0 \\
DO4 & 15.5 & 1.10 & 18.0 & 12.0 & 50.0 \\
DO5 & 4,2 & 1.48 & 24.0 & 12.0 & 50.0 \\
DO6 & 8.3 & 1.48 & 24.0 & 12.0 & 50.0 \\
DO7 & 5.1 & 1.10 & 24.0 & 12.0 & 50.0 \\
DO8 & 8.9 & 1.10 & 24.0 & 12.0 & 50.0 \\
D09 & 7.5 & 1.48 & 24.0 & 12.0 & 100.0 \\
DO10 & 11.3 & 1.48 & 24.0 & 12.0 & 100.0 \\
DO11 & 16.0 & 1.48 & 24.0 & 12.0 & 100.0 \\
D012 & 7.7 & 1.10 & 24.0 & 12.0 & 100.0 \\
D013 & 14.4 & 1.10 & 24.0 & 12.0 & 100.0 \\
D014 & 16.0 & 0.90 & 24.0 & 12.0 & 100.0 \\
\hline
\end{tabular}




\section{DATA ANALYSIS AND RESULTS}

\subsection{Wave transmission analysis and results}

The transmission coefficient $\left(\mathrm{K}_{\mathrm{t}}\right)$ was calculated as the ratio of the average transmitted wave height $\left(\mathrm{H}_{\mathrm{t}}\right)$ obtained from the average of $\mathrm{P}_{4}$ and $\mathrm{P}_{5}$ wave probes in $R M B$ model and the average of $\mathrm{P}_{3}$ and $\mathrm{P}_{4}$ in VB model to the incident wave height $\left(\mathrm{H}_{\mathrm{i}}\right)$ :

$$
\mathrm{K}_{\mathrm{t}}=\frac{\mathrm{H}_{\mathrm{t}}}{\mathrm{H}_{\mathrm{i}}}
$$

Analysis of the transmission coefficient and the effects of different variables (dimensional and nondimensional) on $\mathrm{K}_{\mathrm{t}}$ were examined both graphically and statistically (Brebos and Deves 2007). Based on dimensional analysis (Vartelatou, 2006) the following dimensionless parameters were considered for further analysis:

$$
K_{t}=\frac{H_{t}}{H_{i}}=f\left(\frac{b}{H_{i}}, \frac{d}{H_{i}}, \frac{z}{H_{i}}, \frac{h}{H_{i}}, \frac{\ell}{H_{i}}, \mu\right)
$$

The dimensionless parameter, $\mu\left(\mu=\frac{\sin \phi}{\sqrt{2 \pi \mathrm{H}_{\mathrm{i}} / \mathrm{gT}^{2}}}\right)$, can be used to include wave steepness, where $\sin \varphi$ is the breakwater's slope.

Experimental data were analyzed using a non-linear regression analysis to determine an empirical relationship, which estimates the wave transmission coefficient using as inputs (a) the wave characteristics and (b) the geometrical characteristics of the flushing culvert. In the analysis 155 experimental measurements, i.e. approximately $95 \%$ of the data were used to determine the empirical relationship, by removing randomly $5 \%$ of the data. Then, the remaining $5 \%$ of the data were used for the validation of the equation. The statistical software package SYSTAT v15.0 (SPSS, 2007) was employed to accelerate the analytical process. Equation (3) was found to provide a good representation of the wave transmission through the flushing culvert.

$$
K_{t}=\frac{H_{t}}{H_{i}}=\left(0.135 \frac{b}{H_{i}}+0.026 \frac{d}{H_{i}}+0.030 \frac{z}{H_{i}}+0.048 \frac{h}{H_{i}}-0.036 \frac{\ell}{H_{i}}\right) \mu^{-0.681}
$$

The standard deviation value of Equation (3) was found equal to 0.162 and the correlation coefficient $\left(R^{2}\right)$ equal to 0.783 . Comparison of measured and calculated $K_{t}$ using Equation 3 for all the different series of experiments is shown in Figure 4. It is observed that the predicted $\mathrm{K}_{\mathrm{t}}$ is within the $95 \%$ confidence interval with only 12 data points being outside of this range.

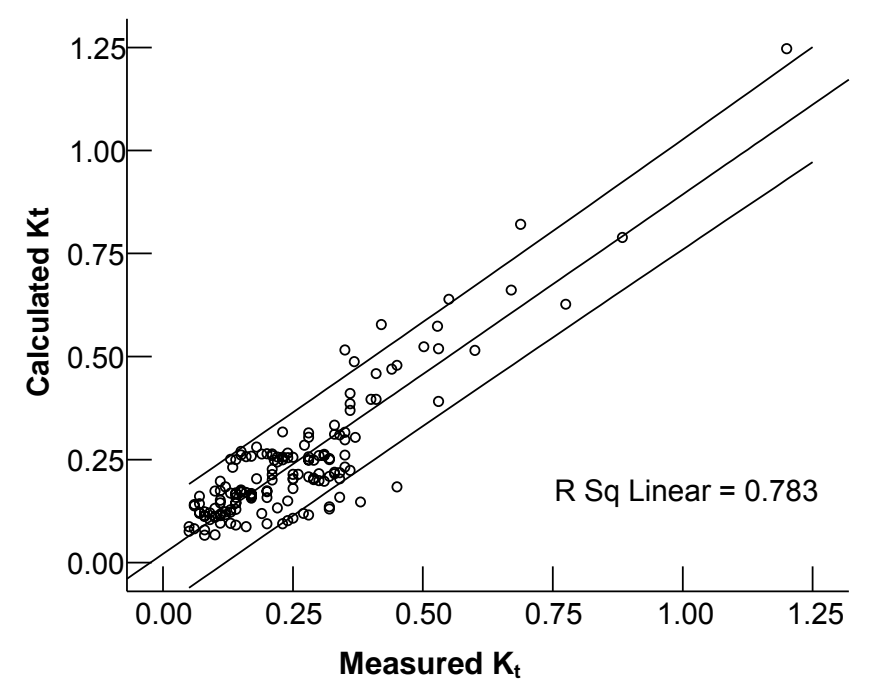

Figure 4. Comparison of measured and calculated $\mathrm{K}_{\mathrm{t}}$ 


\subsection{Dissolved oxygen analysis and results}

DO concentration in the leeside of a flushing culvert calculated by equation:

$$
\frac{\partial C}{\partial t}=k_{D O} \cdot\left(C_{s}-C\right)
$$

where, $C$ is the DO concentration in the leeside of the flushing culvert, $C_{s}$, the saturated DO concentration depended on temperature and pressure, $t$ is time, $k_{D O}$, the oxygen transmission coefficient through flushing culvert, which varies with wave conditions and geometrical characteristiscs of flushing culvert.

The solution of equation (4) can give a function of DO concentration, $C$, with coefficient $k_{D O}$ and time:

$$
C=C_{s}-\left(C_{s}-C_{0}\right) \cdot e^{-k_{D D} \cdot t}
$$

For the initial conditions of $C=C_{0}$ at $t=0$ and assuming constant saturation concentration for the entire experiment, equation (5) can be expressed as a linear function of time:

$$
\ln \left(C_{s}-C\right)=-k_{D O} \cdot t+\ln \left(C_{s}-C_{0}\right)
$$

Based on the available experimental data, $k_{D O}$ coefficients (Gaitanis et al., 2009) were determined by solving equation (6).

Based on dimensional analysis conducted by Vartelatou (2006) and Tsoukala \& Moutzouris (2009) for wave transmission coefficient, the DO transmission coefficient was expressed as a function of the following dimensionless variables:

$$
k_{D O}=\left(\frac{b}{H_{i}}, \frac{\ell}{H_{i}}, T_{i}\right)
$$

where $H_{i}$ and $T_{i}$ are incident wave height and period whereas $b, l$ are flushing culverts' width and length respectively. Note that the height of flushing culvert is omitted from the parameters of concern as there were no available measurements to indicate its effect on oxygen transfer and will be a subject of future research.

After investigating the best fitting equation form with nonlinear regression analysis (SPSS, 2007), the following equation is proposed for the estimation of the oxygen transmission coefficient:

$$
k_{\mathrm{DO}}=\left(0.161-0.024 \frac{b}{H_{i}}-0.002 \frac{\ell}{H_{i}}\right) \times\left(\frac{1}{T_{i}}\right)^{1.364}
$$

The standard deviation value of Equation (3) was found equal to 0.036 and the correlation coefficient $\left(R^{2}\right)$ equal to 0.774 , which can be considered very satisfying. Thus, DO concentration in the leeside of the flushing culvert can be expressed as a function of time, wave conditions and geometrical characteristics of the flushing culvert.

Note that, according to Equation (3), $k_{D O}$ coefficient increases while flushing culvert's width and length decrease. This indicates that openings with sufficient small dimensions in order to allow wave transmission while, at the same time, producing turbulence effects can ease DO transfer through them.

Equation (5) in conjunction with equation (8) can provide the evolution of DO with time in the leeside of a flushing culvert for given conditions of the structure and the wave climate. In addition, using the proposed equation, the demanded time till a given critical concentration is achieved in the harbor basin with given wave conditions for a flushing culvert with specific geometrical characteristics could be estimated.

The evolution of DO in the leeside of the flushing culvert was calculated using equation (5) for the conditions of Table 3 in order to verify the validity of the proposed method. Coefficients $k_{D O}$ for the given conditions were calculated from equation (8). The estimated values were compared with the experimental data. In Figure 5, the evolution of DO estimations with time are plotted for 4 indicative experimental conditions in comparison with the experimental data. It is obvious that estimated values are clearly well representing the measured data. 


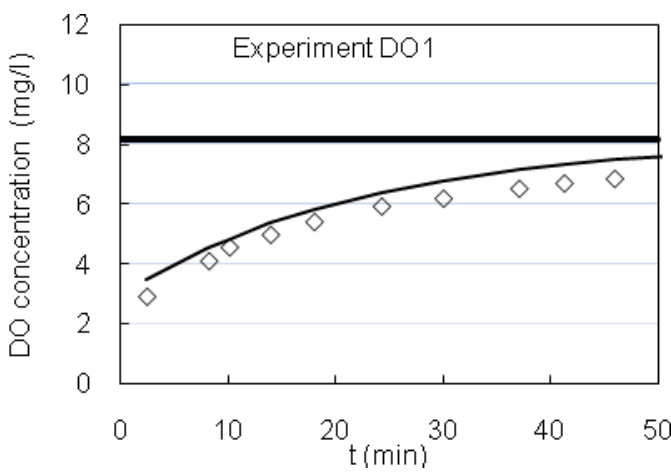

a) $\mathrm{H}=6.3 \mathrm{~cm}, \mathrm{~T}=1.48 \mathrm{sec}$ $\mathrm{b}=18 \mathrm{~cm}, \mathrm{l}=50 \mathrm{~cm}$

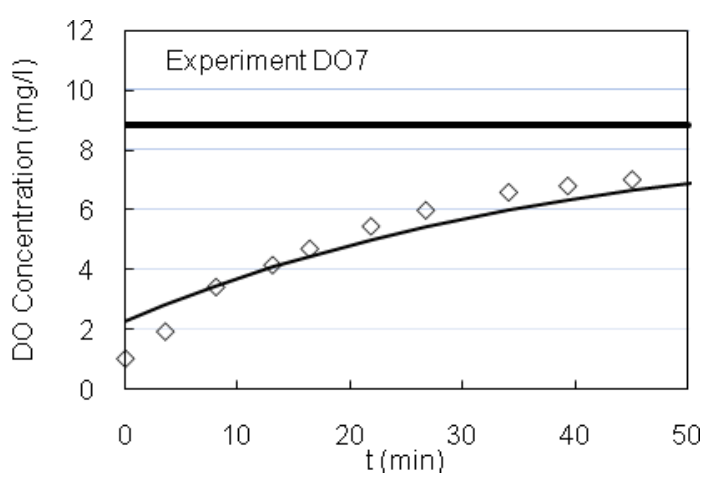

c) $\mathrm{H}=5.1 \mathrm{~cm}, \mathrm{~T}=1.10 \mathrm{sec}$ $\mathrm{b}=24 \mathrm{~cm}, \mathrm{l}=50 \mathrm{~cm}$

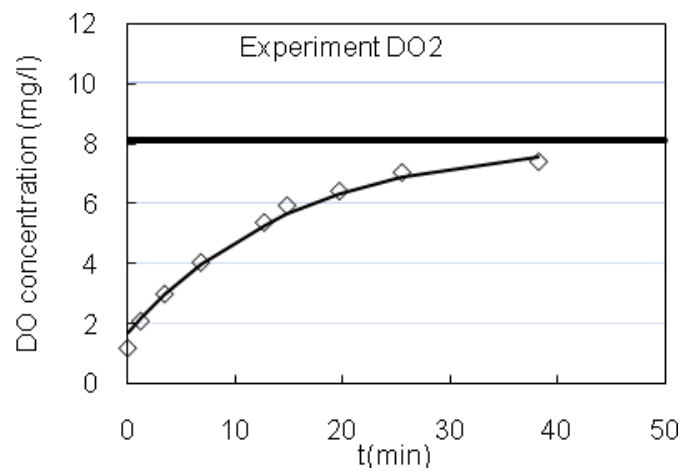

b) $\mathrm{H}=10.7 \mathrm{~cm}, \mathrm{~T}=1.48 \mathrm{sec}$ $\mathrm{b}=18 \mathrm{~cm}, \mathrm{l}=50 \mathrm{~cm}$

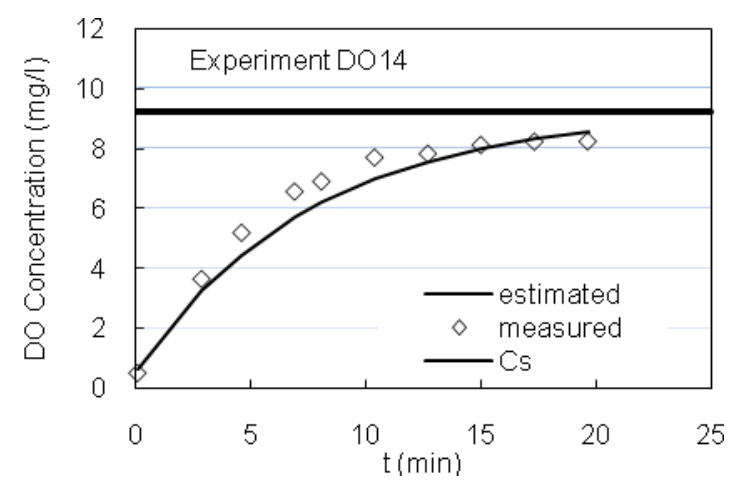

d) $\mathrm{H}=16.0 \mathrm{~cm}, \mathrm{~T}=0.9 \mathrm{sec}$ $\mathrm{b}=24 \mathrm{~cm}, \mathrm{l}=100 \mathrm{~cm}$

Figure 5. Comparison of estimated and measured DO evolution with time for selected experimental conditions

\section{CONCLUSIONS}

In the present paper, results of experiments carried out in the 2-D facility of LHW in order to investigate wave and dissolved oxygen transmission in harbor basins through flushing culverts are presented and analyzed. The flushing culvert is embodied in physical models of breakwaters with vertical as well as with sloping seaside profiles.

An empirical equation using regression analysis for the $95 \%$ of the data was derived, which correlates the wave transmission coefficient $\mathrm{K}_{\mathrm{t}}$, with the characteristics of the waves and the geometrical characteristics of the flushing culverts; this equation was successfully verified using the rest $5 \%$ of the data and can be used in the preliminary design of flushing culverts.

For the estimation of DO concentration in the leeside of the flushing culvert during time an empirical equation was also proposed. The oxygen transmission coefficient through flushing culverts, $k_{D O}$, was expressed as a function of the characteristics of waves approaching the breakwater and the dimensions of the flushing culvert. The comparison of calculated and experimental data is very encouraging.

The proposed equation seems to be a satisfactory preliminary approximation and could be used for the estimation of the transmission coefficient. According to the scales of the tested physical models, a quite well prediction is expected for waves with heights between $0.15-2.5$ $\mathrm{m}$ and periods 3.5 - $5.75 \mathrm{sec}$. However, as these equations derived from laboratory experiments possible scale effects are fomented in the results. To overcome this uncertainty, further experiments should be undertaken in different scales for both regular and irregular waves. Finally measurements in nature are needed to be conducted for the validation of the 
proposed equation and the optimization of the coefficients derived from the regression analysis.

\section{ACKNOWLEDGEMENTS}

This paper is partly funded by the National Technical University of Athens within the framework of LEFKIPOS Project.

\section{REFERENCES}

1. Bersford, P.J., Spencer, J.M.A, Clarke, J. (2005), HR Wave Data-Data Acquisition and analysis software program User manual, Report IT 493, H.R. Wallingford.

2. Brebos, E. and Deves, D. (2007), Experimental investigation of wave transmission through flushing culverts in harbor basin, Master thesis, Laboratory of Harbor Works, National Technical University of Athens, p.126.

3. Dunham, J.W. and Finn, A.A. (2002), Small-craft harbors: Design, construction and operation, Fredonia Books, Amsterdam, The Netherlands, p. 375.

4. EPA (2001), National Management Measures Guidance to Control Non-point Source Pollution from Marinas and Recreational Boating, EPA841-B-01-005.

5. Fountoulis, G. and Memos, C. (2005), Optimization of Openings for Water Renewal in a Harbor Basin, Journal of Marine Environmental Engineering, 7 (4), pp. 297-306.

6. Gaitanis, C.K., Douka, E., Tsoukala, V.K., Stamou, A.I. and Moutzouris, C.I. (2009), Dissolved oxygen transmission in harbor basins through flushing culverts, $11^{\text {th }}$ Internation Conference on Environmental Science and Technology, Chania, Crete, Greece (accepted).

7. Karydis, M. (2009), Eutrophication assessment of coastal waters based on indicators: a literature review, Global Nest, 11 (4), pp. 373-390.

8. Nikolaou, A., Kostopoulou, M., Lofrano, G., Meric, S. (2009), Determination of PAHs in marine sedimentsQanalytical methods and environmental concerns, Global Nest, 11 (4), pp. 391-405.

9. SPSS Inc., (2007), SYSTAT ${ }^{\circledR}$ v.14.0. Technical Software.

10. Stamou, A.I., Katsiris, I.K., Moutzouris, C.I. and Tsoukala, V.K. (2004), Improvement of Marina Design Technology Using Hydrodynamic Models, Global Nest, 6 (1), pp. 63-72.

11. Tsoukala, V.K. and Moutzouris, C.I. (2003), Field measurements of marina flushing and dissolved oxygen penetration in a harbor basin through water entrance channels, $3^{\text {rd }}$ Panhellenic Conference of Harbor Works, Athens, pp 607-619.

12. Tsoukala, V.K. and Moutzouris, C.I. (2009), Wave transmission in harbors through flushing culverts, Ocean Engineering, 36, 434-445.

13. Vartelatou, S.P. (2006), Dimensional analysis of wave transmission through flushing culverts, Master thesis, Laboratory of Harbor Works, National Technical University of Athens, p. 174.

14. http://www.ysi.com/media/pdfs/605348-YSI-550A-Operations-Manual-RevB_001.pdf.

15. US Army Corps of Engineers (2002), Coastal Engineering Manual (CEM), EM 1110-2-1100. 